\title{
Zoneamento Ecológico-Econômico como política pública para o Estado de Mato Grosso do Sul
}

\section{Ecological-Economic Zoning as a public policy for the Mato Grosso do Sul State \\ Zonificación Ecológica-Económica como política pública para el Estado de Mato Grosso do Sul}

\section{Écologique-Economique Zonage et la politique publique d'État du Mato Grosso do Sul}

\author{
Thiago de Andrade Neves ${ }^{1}$ \\ Leandro Sauer ${ }^{2}$
}

Recebido em 25/03/2016; revisado e aprovado em 24/08/2016; aceito em 06/10/2016

DOI: http://dx.doi.org/10.20435/inter.v18i3.717

\begin{abstract}
Resumo: Este trabalho objetivou apresentar a Política Nacional do Meio Ambiente no âmbito de seu Zoneamento Ecológico-Econômico, apontando a legislação pertinente, a sua metodologia, caracterizando-o como uma Política Pública no estado de Mato Grosso do Sul.

Palavras-chave: Zoneamento Ecológico-Econômic; Política Pública; Gestão Territorial.
\end{abstract}

\begin{abstract}
This study aims to present the National Environmental Policy within their ecological zoning, identifying the relevant legislation, its methodology, characterizing it as a public policy in the state of Mato Grosso do Sul.
\end{abstract}

Key words: Ecological-Economic Zoning; Public Policies; Land Management.

Résumé: Cette étude vise à présenter la politique nationale de l'environnement au sein de leur zonage écologique, montrant la législation pertinente, sa méthodologie, le caractérisant comme une politique publique dans l'État du Mato Grosso do Sul.

Mots-clés: Zonage Écologique-Économique; Politique Publique; Gestion des Terres.

Resumen: Este estudio tiene como objetivo presentar la Política Nacional de Medio Ambiente dentro de su zonificación ecológica, exhibiendo a la legislación pertinente, su metodología, caracterizándolo como una política pública en el estado de Mato Grosso do Sul.

Palabras clave: Zonificación Ecológica-Económica; Políticas Públicas; Manejo del Territorio.

\section{INTRODUÇÃO}

Historicamente, as teorias e conceitos de desenvolvimento sempre estiveram atrelados a alguma resultante do crescimento econômico. Todavia, com o passar do tempo e, consequentemente, com a construção de novas abordagens, a questão territorial foi galgando importante espaço na análise conceitual nos estudos sobre desenvolvimento, rompendo com a ideia de que ele se restringe ao aspecto econômico, incorporando outras dimensões a serem observadas como as sociais, políticas, institucionais e ambientais (PEREIRA et al., 2011).

Com este horizonte multidisciplinar, tornou-se necessária a criação de instrumentos que contemplem todos estes arcabouços na coleta de informações essenciais para o planejamento e gestão de políticas efetivas com viés no desenvolvimento, uma vez que os esforços anteriormente propostos sobre o tema esbarravam na total ignorância ou na deficiência de informações consistentes dentro da administração pública.

\footnotetext{
${ }^{1}$ Universidade de São Paulo (USP), São Paulo, SP, Brasil.

${ }^{2}$ Universidade Federal de Mato Grosso do Sul (UFMS), Campo Grande, Mato Grosso do Sul, Brasil.
} 
Convergindo para essa ideia, o Estado, através de sua Política Nacional do Meio Ambiente (BRASIL, 1981), vem trabalhando para criar elementos que levem em conta as peculiaridades de um país com tantas especificidades e diversidades quanto o Brasil, "integrando-o aos sistemas de planejamento em todos os níveis da administração pública e gerenciando-o, em diversas escalas de tratamento, as informações necessárias à gestão do território" (MINISTÉRIO DO MEIO AMBIENTE [MMA], 2006).

A exploração de atividades de impacto ambiental não exige apenas uma fiscalização próxima e perene, "mas também a incorporação de novas tecnologias, processos e programas que viabilizem o equacionamento entre crescimento econômico e qualidade ambiental" (LEITE, 2015, p. 170).

Um dos pontos mais importantes nesse novo escopo está no dispositivo legal que estabeleceu esta Política do Meio Ambiente, o qual prevê o zoneamento ambiental como um de seus instrumentos ${ }^{3}$, regulamentado apenas em 2002 pelo Decreto n. 4.297 (BRASIL, 2002) denominando-o Zoneamento Ecológico-Econômico (ZEE). Todavia, uma vez que o conceito legal desse ZEE suscita questões polêmicas, na medida em que até mesmo a sua definição está eivada de discussões quanto a sua aplicação e eficácia (LIMA, 2012, p. 93), este trabalho tem o objetivo de realizar um estudo sobre o ZEE de Mato Grosso do Sul com o intuito de aferir se ele pode ser considerado, de fato, uma política pública para o estado.

A relevância de tal caracterização reside no fato de que as políticas públicas, diferentemente das políticas de governos e das ações governamentais, transcendem ao mandato eleitoral, adotando, assim, características peculiares, conforme serão ressaltadas neste trabalho, as quais tornam essas políticas muito mais abrangentes e eficazes para a sociedade.

Destarte, este trabalho tem o objetivo de realizar um breve estudo sobre as Políticas Públicas, classificar teórica e metodologicamente o Zoneamento Ecológico-Econômico, para, assim, identificar ou afastar este ZEE/MS como, de fato, uma política pública para o Estado de Mato Grosso do Sul.

\section{ZONEAMENTO ECOLÓGICO-ECONÔMICO}

Embora não existam fases definidas da evolução fática e normativa (PAULINO, 2010, p. 22), observa-se que há décadas que o Estado vem se esforçando para trazer o tema para sua pauta de atuação, culminando, finalmente em 2002, com o Decreto n. 4.297.

Essa norma instituiu critérios para a sua criação e definiu o ZEE como sendo um instrumento de organização do território, sendo obrigatória sua obediência para a "implementação de planos, obras e atividades públicas e privadas", estabelecendo, ainda, "medidas e padrões de proteção ambiental destinados a assegurar a qualidade ambiental, dos recursos hídricos e do solo e a conservação da biodiversidade, garantindo o desenvolvimento sustentável e a melhoria das condições de vida da população" (BRASIL, 2002):

O decreto do ZEE afirma que este instrumento encontra fundamento jurídico nos arts. 21, inc. IX, 170, inc. VI, 186, inc. II, e 225 da Constituição, e na Lei de Política Nacional de Meio Ambiente, n.o 6.938, de 31.08.1981, e que sua elaboração, interpretação e implementação obedecerão aos princípios da função socioambiental da propriedade, da prevenção, da precaução, do poluidor-pagador, do usuário-pagador, da participação informada, do acesso equitativo e da integração. (LIMA, 2012, p. 122).

\footnotetext{
3 "São instrumentos da Política Nacional do Meio Ambiente: [...] II - o zoneamento ambiental" (BRASIL, 1981).
} 
Pelo Decreto n. 4.297/2002, é previsto que o objetivo do ZEE é "organizar, de forma vinculada, as decisões dos agentes públicos e privados quanto a planos, programas, projetos e atividades que, direta ou indiretamente, utilizem recursos naturais, assegurando a plena manutenção do capital e dos serviços ambientais dos ecossistemas" (BRASIL, 2002).

Por meio do Ministério do Meio Ambiente, tem-se que o Zoneamento Ecológico-Econômico "tem como objetivo viabilizar o desenvolvimento sustentável a partir da compatibilização do desenvolvimento socioeconômico com a proteção ambiental" (MMA, s.d.). Nela há uma "divisão de determinado território em zonas ou áreas em que se autorizam determinadas atividades ou se interdita, de modo absoluto ou relativo, o exercício de outras atividades em razão das características ambientais ou socioeconômicas do local" (REMPEL et al., 2012, p. 91).

Conforme afirma Lima (2012, p. 17), o ZEE foi criado através de "um dos principais 'consensos' para orientar a definição das dimensões (percentual mínimo) das áreas a serem conservadas ou convertidas para uso agropecuário nas propriedades rurais em função do bioma abrangido e da região geográfica".

Nas lições de Leite (2015, p. 181):

[...] o ZEE busca contribuir para racionalizar o uso e a gestão do território, reduzindo as ações predatórias e apontando as atividades mais adaptadas às particularidades de cada região, melhorando a capacidade de percepção das inter-relações entre os diversos componentes da realidade e, por conseguinte, elevando a eficácia e efetividade dos planos, programas e políticas, públicos e privados, que incidem sobre um determinado território, espacializando-os de acordo com as especificidades observadas.

Essa lei sugere, portanto, que sejam divididas áreas com diferentes biomas denominando-as zonas, fazendo com que esse fracionamento territorial se torne "um instrumento dos mais importantes para o planejamento ambiental, pois permite tratar a espacialização dos atributos ambientais, bem como de suas potencialidades, vocações, fragilidades, riscos e conflitos" (VASCONCELOS et al., 2013, p. 121). Regulamenta, assim, o uso do território, através do resultado de estudos e planejamentos que almejam a compatibilização da proteção do meio ambiente e o desenvolvimento da atividade humana (PAULINO, 2010, p. 39).

Destarte, pode-se dizer que o ZEE conjuga aspectos ecológicos e socioeconômicos com o intuito de se induzir um melhor uso do solo, percebendo as potencialidades e os riscos associados ao processo da utilização do solo em regiões diferentes (VANSCONCELOS et al., 2013, p. 122).

Cada parte dessa divisão é interpretada multidisciplinarmente e de forma individual, sendo estabelecidos pelos órgãos públicos regimes especiais de "uso, gozo e fruição da propriedade na busca da melhoria e recuperação da qualidade ambiental e do bem-estar da população" (REMPEL et al., 2012, p. 91), o que se dá por meio de leis específicas, tanto no âmbito federal, quanto na esfera estadual.

\subsection{Metodologia aplicada ao Zoneamento Ecológico-Econômico}

Uma vez que para a execução do Zoneamento Ecológico-Econômico são necessárias diversas ações descentralizadas em todas as esferas da administração, o Ministério do Meio Ambiente publicou uma série de documentos denominados Diretrizes Metodológicas para o Zoneamento Ecológico-Econômico do Brasil (MMA, 2006) na tentativa de uniformizar a metodologia do ZEE no território nacional com os seguintes objetivos:

São objetivos gerais do Projeto ZEE Brasil: 
- Subsidiar a elaboração de macropolíticas territoriais, orientando os tomadores de decisão na adoção de políticas convergentes com as diretrizes de planejamento estratégico do país.

- Instituir e montar um banco de dados com as informações ambientais e socioeconômicas, necessárias ao planejamento macrorregional.

- Apoiar os empreendimentos federais, no que concerne à implantação de políticas setoriais e à infraestrutura conexa.

- Fornecer aos Estados e Municípios diagnósticos gerais e uma perspectiva global sobre a realidade do país, bem como as diretrizes gerais do ZEE propostas pelo Governo Federal.

São objetivos específicos do Projeto ZEE Brasil:

- Avaliar os componentes dos sistemas ambientais naturais quanto às suas potencialidades e limitações atuais e às tendências de desenvolvimento socioeconômico.

- Incentivar estudos qualitativos e quantitativos sobre os recursos naturais e sociais disponíveis em cada sistema e subsistema ambiental para aumentar a capacidade de análise dos projetos.

- Elaborar bases para os modelos ambientais (naturais e antrópicos) e os cenários exploratórios, quanto aos impactos ambientais e sociais prognosticados.

- Contribuir para definir Políticas de Desenvolvimento com base na sustentabilidade e potencialidades ambientais e sociais.

- Elaborar diagnósticos ambientais e prognósticos de impactos positivos e negativos necessários para orientar estudos de empreendimentos projetados, segundo os modelos e cenários alternativos apresentados. (MMA, 2006).

Como forma de facilitar os procedimentos operacionais, o MMA (2006) dividiu metodologicamente a execução do projeto de ZEE em quatro fases de trabalho: planejamento do projeto; diagnóstico, prognóstico e a implementação, de acordo com a Figura 1.

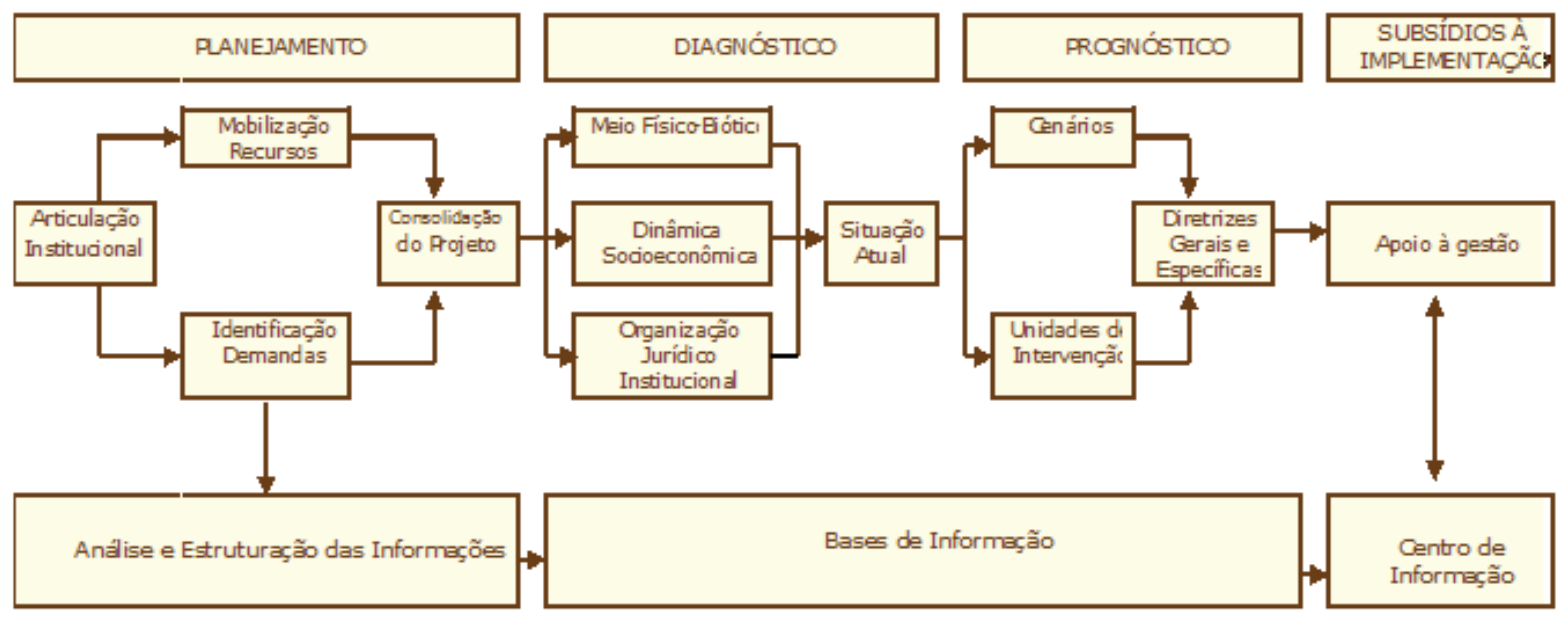

Figura 1- Fluxograma das principais atividades do ZEE Fonte: MMA (2006).

O planejamento é o ponto de partida do zoneamento, ocorrendo antes de qualquer estudo técnico do ZEE. "Sua importância consiste em planejar a execução dos trabalhos de acordo com os objetivos propostos e os problemas a serem resolvidos" (MMA, 2006). Abrange a articulação institucional; mobilização de recursos; identificação de demandas; análise e estruturação das informações; consolidação do projeto (MMA, 2006).

Uma vez ultrapassadas todas as fases do planejamento, o projeto do ZEE é submetido à etapa de diagnóstico. Aqui, o estudo é apresentado em níveis diferenciados de integração 
visando a todas as dimensões a ele integradas: meio físico-biótico; dinâmica socioeconômica; diagnóstico da organização jurídico-institucional; situação atual.

Superado o diagnóstico, nos termos da metodologia idealizada pelo Ministério do Meio Ambiente, passa-se à fase do prognóstico. Nesta etapa se discutem as possibilidades e condições de se normatizar legalmente e/ou programaticamente o ZEE, possibilitando que ele regulamente e promova usos compatíveis com a sustentabilidade ecológica, social e econômica das diferentes unidades ambientais definidas na etapa anterior, além de estabelecer critérios e princípios que orientem o desenvolvimento, corrigindo e superando desequilíbrios econômicos e ambientais, protegendo os recursos naturais e elevando a qualidade de vida social: proposição das unidades de conservação; cenários; zonas de proposição de diretrizes gerais e específicas (MMA, 2006).

Por fim, após a constituição dos parcelamentos, tem-se a fase de subsídios à implementação do ZEE. Nesta etapa, é fundamental que o instrumento esteja assimilado, difundido e que esteja inferido nos programas dos órgãos que compõem o Projeto ZEE Brasil e é constituída pelo apoio à gestão: plano contínuo de coleta, tratamento, atualização e disseminação de informações; mecanismo de subsídio contínuo à implementação das estratégias de desenvolvimento nas zonas estabelecidas; monitoramento contínuo da situação das zonas estabelecidas; apoio técnico à regulamentação de diretrizes legais propostas com interlocução nas casas legislativas; e referência matricial com as instituições envolvidas com o PPA (MMA, 2006).

\section{POLÍTICAS PÚBLICAS}

O Estado não tem apenas a prerrogativa, mas possui como uma das finalidades promover o desenvolvimento, a ordem e a paz em todos os campos que engloba a sociedade. Conforme salienta Carvalho (2003, p.81), o Estado "existe para realizar a segurança, a justiça e o bem-estar econômico e social, os quais constituem o seu fim", e as políticas públicas traduzem efetivamente esse dever estatal uma vez que "são formas de planejamento governamental. Elas envolvem atores sociais, meios e recursos do Estado e do setor privado" (KAUCHAKJE, 2012, p. 76).

Em linhas gerais, "a função primordial do governo, uma primeira definição de política pública pode ser formulada como sendo o conjunto de princípios, critérios e linhas de ação que garantem e permitem a gestão do Estado na solução dos problemas nacionais" (DIAS; MATOS, 2012, p. 12).

Sendo um conceito de Política e da Administração, conforme sugere Souza (2006), a política pública é:

[...] o campo do conhecimento que busca, ao mesmo tempo, 'colocar o governo em ação' e/ou analisar esta ação (variável independente) e, quando necessário, propor mudanças no rumo ou curso dessas ações (variável dependente). A formulação de políticas públicas constitui-se no estágio em que os governos democráticos traduzem seus propósitos e plataformas eleitorais em programas e ações que produzirão resultados ou mudanças no mundo real. (SOUZA, 2006, p. 26).

Para Leonardo Secchi (2014, p. 2), “uma política pública possui dois elementos fundamentais: intencionalidade pública e resposta a um problema público; em outras palavras, a razão para o estabelecimento de uma política pública é o tratamento ou a resolução de um problema entendido como coletivamente relevante".

Através dos conceitos e modelos trazidos em seu trabalho, Souza (2010, p. 72) sintetizou as políticas públicas como sendo um instituto que: permite distinguir o que o governo pretende 
fazer e o que realmente faz; é abrangente e não se limita a leis e regras; é uma ação intencional, com objetivos a serem alcançados; apesar de impactar no curto prazo, é uma política de longo prazo; e envolve processos após sua decisão, como: implementação, execução e avaliação.

Uma vez que as suas formulações e a implementações tomam a forma e a expressão das relações e das forças sociais em disputa (DEITOS, 2010, p. 210), o Desenvolvimento Sustentável foi ocupando um espaço cada vez mais robusto junto à sociedade de forma que as políticas públicas foram convergindo para a tutela e a exploração do meio ambiente.

Destarte, tem-se que a atividade do poder público transcende as rotinas administrativas corriqueiras, uma vez que é composta por um complexo organismo que precisa funcionar e apresentar resultados que visam ao bem comum da sociedade, formulando, mediando, implementando, monitorando e avaliando programaticamente por meio das políticas públicas.

\subsection{Características das Políticas Públicas}

Por serem, via de regra, executadas pela União, estados e municípios, as políticas públicas devem estar revestidas do princípio da legalidade ${ }^{4}$. Assim, as políticas públicas "são formas de aplicação dos artigos constitucionais e das leis que os regulamentarem" (KAUCHAKJE, 2012, p. 79), traduzindo-se como meios de concretização dos direitos previstos em nosso ordenamento jurídico, mesmo que suas iniciativas e decisões sejam oriundas em diversas origens (SECCHI, 2014, p. 3)

Note-se que a legislação, notadamente a Constituição da República, prevê os direitos da sociedade de forma ampla, sendo traduzidos por meio das políticas públicas que, por sua vez, estão subordinadas às decisões políticas tomadas no seio do governo com participação da sociedade civil, onde estão fixados os meios, os agentes e os fins das ações a serem executadas para que não fujam dos objetivos estabelecidos (DIAS; MATOS, 2012, p. 15).

Uma vez que política pública é uma conceito abstrato que se materializa através de instrumentos variados (SECCHI, 2014, p. 11), o Banco Interamericano de Desenvolvimento (BID) aponta que ela deve ser analisada pelas seguintes características:

- Estabilidade - em que medida as políticas são estáveis ao longo do tempo.

- Adaptabilidade - em que medida as políticas podem ser ajustadas quando falham ou quando as circunstâncias mudam.

- Coerência e coordenação - em que grau as políticas são compatíveis com outras políticas afins e resultam de ações bem coordenadas entre os atores que participam de sua formulação e implementação.

- Qualidade da implementação e da aplicação efetiva.

- Consideração do interesse público - em que grau as políticas tendem ao interesse público.

- Eficiência: em que medida as políticas refletem uma alocação de recursos escassos que assegure retorno sociais elevados. (BID, 2007, p. 130).

Portanto, no iter de toda a construção e efetivação das políticas públicas, tais características devem estar inseridas em seu contexto, construídas por meio de seus ciclos.

Embora haja certa consonância entre os autores das fases que compõem os ciclos de políticas pública (DIAS; MATOS, 2012; SARAIVA, 2006; SEBRAE, 2008; SOUZA, 2006), este trabalho utilizará a classificação trazida por Secchi (2014, p.43), na qual o modelo foi restrito "às sete

\footnotetext{
${ }^{4}$ É o princípio da Administração Pública previsto pelo Art. 37 da CR/88. Conforme Meirelles (2010, p. 86), "enquanto na administração particular é lícito fazer tudo que a lei não proíbe, na Administração Pública só é permitido fazer o que a lei autoriza. A lei para o particular significa 'pode fazer assim', para o administrador público significa 'deve fazer assim'”.
} 
fases principais:

1) identificação do problema, momento em que se observa a carência ou excesso em um setor específico da sociedade ou alguma incongruência política que cause "discrepância entre o status quo e uma situação ideal possível" (SECCHI, 2014, p. 44);

2) formação da agenda, momento quando se decide se o problema público deve ser posto em pauta política "ou se deve ser excluído ou adiado para uma data posterior, e isso independentemente de sua relevância para a ação. Para que essa decisão seja tomada, é necessária pelo menos uma avaliação preliminar sobre custos e benefícios das várias opções disponíveis de ação" (DIAS; MATOS, 2012, p. 70);

3) formulação de alternativas, também citada com formulação de política (DIAS; MATOS, 2012; SEBRAE, 2008) depois da inserção do problema na agenda, iniciam-se os esforços de construção e a combinação de solução para a formulação de alternativas;

4) tomada de decisão, embora em todo momento no ciclo de política pública decisões sejam tomadas, este estágio é definido como "o momento quando se escolhe alternativas de ação/ intervenção em resposta aos problemas definidos na Agenda" (SEBRAE, 2008, p. 13), ou seja, aqui "os interesses dos atores são equacionados e as intenções (objetos e métodos) de enfrentamento de um problema público são explicitadas" (SECCHI, 2014, p. 51);

5) implementação, quando o planejamento escolhido através das etapas ultrapassadas anteriormente tomam corpo e começam a ser executados pela administração pública ou através dela. Para Saraiva (2006, p. 37), esta etapa é "constituída pelo planejamento e organização do aparelho administrativo e dos recursos humanos, financeiros, materiais e tecnológicos necessários para executar uma política";

6) avaliação, é área da política pública que mais se desenvolveu ultimamente, se traduzindo na "mensuração, a posteriori, dos efeitos produzidos na sociedade pelas políticas públicas, especialmente no que diz respeito às realizações obtidas e às consequências previstas e não previstas" (SARAIVA, 2006, p. 34-35);

7) extinção, pode ter, basicamente, três causas: o problema inicial é tido como resolvido; a política é percebida como ineficaz; ou, embora não resolvido, o problema perdeu a sua importância, saindo da agenda de ação do Estado (SECCHI, 2014, p. 67).

\section{CONCLUSÕES}

Nos termos discorridos neste trabalho, o programa de Zoneamento Ecológico-Econômico de Mato Grosso do Sul trata-se, conforme disposição legal, de um "instrumento de organização do território a ser obrigatoriamente seguido" (BRASIL, 2002) na consecução de inúmeras atividades exercidas pelo poder estatal e pela iniciativa privada.

Em linha gerais, o ZEE busca a "sustentabilidade ecológica, econômica e social, com vistas a compatibilizar o crescimento econômico e a proteção dos recursos naturais, em favor das presentes e futuras gerações" (BRASIL, 2002).

Conforme argumentou-se neste trabalho, as políticas públicas transcendem as meras políticas de governo e as ações governamentais, uma vez que estão eivadas de características no tocante à estabilidade no tempo, eficiência e o zelo ao interesse público.

De acordo com os instrumentos legais, assim como os demais documentos elaborados pelo poder público atinentes à matéria, localizam-se intrínseca e extrinsecamente, todos os elementos 
necessários para que se considere o Zoneamento Ecológico-Econômico de Mato Grosso do Sul como, de fato, uma política pública, senão vejamos.

Primeiramente por, como apontado reiteradamente neste trabalho, ser de obediência obrigatória, uma vez que decorre de lei, nos termos do art. 2o do Decreto 4.297/2002 que regulamentou o Zoneamento Ecológico-Econômico, parte integrante da Política Nacional do Meio Ambiente (BRASIL, 1981).

Mesmo desconsiderado o imperativo legal, nos moldes dos conceitos aqui aduzidos sobre o tema (DIAS; MATOS, 2012; SECCHI, 2014), tem-se que políticas públicas são tanto um conjunto de princípios, critérios e linhas de ação, como também possuem uma intencionalidade pública em resposta a um problema de relevância social, qualidades estas preenchidas pela política de meio ambiente instituída no país (BRASIL, 1981).

Mesmo que se observe disparidade entre os programas de ZEE que são levados a cabo de norte a sul do país, a intencionalidade, metodologia relativamente homogênea, estabilidade temporal e o cumprimento regular dos ciclos inerentes às políticas públicas, tem-se que a administração abraça o Zoneamento Ecológico-Econômico como de fato uma política pública nacional, nos termos já previstos e tutelado pela legislação nacional.

Considerando, ainda, o rol de atributos utilizados pelo Banco Interamericano de Desenvolvimento para a caracterização das políticas públicas, nota-se que todas eles estão presentes no Zoneamento Ecológico-Econômico já que se resumem a: estabilidade; adaptabilidade; coerência e coordenação; qualidade da implementação e da aplicação efetiva; consideração do interesse público; e eficiência (BID, 2007), elementos estes encontrados na Política Nacional do Meio Ambiente.

No estado de Mato Grosso do Sul, pode-se dizer que, após a aprovação de sua lei de Zoneamento Ecológico-Econômico (MATO GROSSO DO SUL, 2009), iniciou-se a fase de implementação dessa política pública em seu território, ocorrendo tanto nos modelos de cima para baixo, quanto no de baixo para cima.

Já em relação à metodologia específica do ZEE, conforme apontado por meio das diretrizes do MMA (2006), nota-se que esta política pública ultrapassou recentemente, após a edição da lei estadual, a fase do diagnóstico para o prognóstico, uma vez que o parcelamento do estado foi realizado, sem ocorrer, contudo, os avanços metodológicos e práticos significativos após esse zoneamento.

Após o grande salto dessa política pública com a publicação da lei específica para o estado de Mato Grosso do Sul, o desaparelhamento e a inércia relacionada ao ZEE/MS por parte da atual gestão estadual aparentemente estagnou tal avanço, destoando com o proposto pelas leis federal e estadual relacionado ao Programa Nacional de Zoneamento Ecológico Econômico.

\section{REFERÊNCIAS}

BANCO INTERAMERICANO DE DESENVOLVIMENTO (BID). A política das políticas públicas: progresso econômico e social na América Latina: Relatório 2006. Rio de Janeiro: Elsevier, 2007.

BRASIL. Decreto n. 4.297, de 10 de julho de 2002. Regulamenta o art. 9o, inciso II, da Lei n. 6.938, de 31 de agosto de 1981, estabelecendo critérios para o Zoneamento Ecológico-Econômico do Brasil - ZEE, e dá outras providências. Disponível em: <http://www.planalto.gov.br/ccivil_03/decreto/2002/d4297. htm>. Acesso em: 28 mar. 2015.

. Decreto n. 7.378, de 1ㅇ de dezembro de 2010. Aprova o Macrozoneamento Ecológico-Econômico da Amazônia Legal - MacroZEE da Amazônia Legal, altera o Decreto n. 4.297, de 10 de julho de 2002, 
e dá outras providências. Disponível em: <http://www.planalto.gov.br/ccivil_03/_Ato2007-2010/2010/ Decreto/D7378.htm>. Acesso em: 5 out. 2015.

. Lei n. 6.938, de 31 de agosto de 1981. Dispõe sobre a Política Nacional do Meio Ambiente, seus fins e mecanismos de formulação e aplicação, e dá outras providências. Disponível em: <http://www. planalto.gov.br/ccivil_03/Leis/L6938.htm>. Acesso em: 10 jul. 2015.

CARVALHO, Kildare Gonçalves. Direito Constitucional Didático. 9. ed. Belo Horizonte: Del Rey, 2003.

DEITOS, Roberto Antônio. Políticas públicas e educação: aspectos teórico-ideológicos e socioeconômicos. Acta Scientiarum Education, Maringá, PR, v. 32, n. 2, p. 209-218, 2010.

DIAS, Reinaldo; MATOS, Fernanda. Políticas públicas: princípios, propósitos e processos. 1. ed. São Paulo: Atlas, 2012.

KAUCHAKJE, Samira. Gestão pública de serviços sociais. 1. ed. Curitiba: Intersaberes, 2012.

LEITE, José Rubens Morato (Coordenador). Manual de Direito Ambiental. 1. ed. São Paulo: Saraiva, 2015. LIMA, André. Zoneamento ecológico-econômico à luz dos direitos socioambientais. 1. ed. Curitiba: Juruá, 2012. MATO GROSSO DO SUL [Governo do Estado de]. Lei n. 3.839, de 28 de dezembro de 2009. Institui o Programa de Gestão Territorial do Estado de Mato Grosso do Sul (PGT/MS); aprova a Primeira Aproximação do Zoneamento Ecológico-Econômico do Estado de Mato Grosso do Sul (ZEE/MS), e dá outras providências. Disponível em: <http://faolex.fao.org/docs/texts/bra116233.doc>. Acesso em: 10 abr. 2015.

MEIRELLES, Hely Lopes. Direito Administrativo brasileiro. 36. ed. São Paulo: Malheiros, 2010.

MINISTÉRIO DO MEIO AMBIENTE (MMA). Diretrizes metodológicas para o Zoneamento EcológicoEconômico do Brasil. 2006. Disponível em: <http://www.mma.gov.br/estruturas/PZEE/_arquivos/ diretrizes_2006_parte1.pdf>. Acesso em: 20 set. 2015

Zoneamento ecológico-econômico. [s.d.]. Disponível em: <http://www.mma.gov.br/gestaoterritorial/zoneamento-territorial>. Acesso em: 20 set. 2015.

OLLAIK, Leila Giandoni; MEDEIROS, Janann Joslin. Instrumentos governamentais: reflexões para uma agenda de pesquisas sobre implementação de políticas públicas no Brasil. Revista de Administração Pública. 45(6): 1943-67. Rio de Janeiro, nov./dez. 2011.

PAULINO, Heloisa Verri. Zoneamento ambiental: uma visão panorâmica. 2010. 549f. Dissertação (Mestrado em Direito das Relações Sociais: Direitos Difusos e Coletivos) - Pontifícia Universidade Católica de São Paulo, São Paulo, 2010.

PEREIRA, José Roberto; FERREIRA, Patrícia Aparecida; BOAS, Ana Alice Vilas; OLIVEIRA, Elias Rodrigues de; CARDOSO, Raquel Finamor. Gestão social dos territórios da cidadania: o zoneamento ecológico-econômico como instrumento de gestão do território noroeste de Minas Gerais. Cadernos EBAPE.BR, Rio de Janeiro, v. 9, n. 3, artigo 3, p. 725-747, set. 2011.

REMPEL, Claudete; ECKHARDT, Rafael Rodrigo; SCHULTZ, Glauco; PÉRICO, Eduardo; CYRNE, Carlos Cândido da Silva. Zoneamento Ecológico-Econômico - ZEE - Para Sistemas Orgânicos de Produção Agropecuária. TECNO-LÓGICA, Santa Cruz do Sul, RS, v. 16, n. 2, p. 90-97. jul./dez. 2012.

SARAIVA, Enrique. Introdução à teoria da política pública. In: SARAIVA, Enrique; FERRAREZI, Elisabete (Org.). Políticas públicas - coletânea. Brasília: ENAP, 2006. (Vol. 1)

SERVIÇO BRASILEIRO DE APOIO ÀS MICRO E PEQUENAS EMPRESAS/MG (SEBRAE/MG). Políticas públicas: conceitos e práticas. Supervisão de Brenner Lopes e Jefferson Ney Amaral; Coordenação de Ricardo Wahrendorff Caldas. Belo Horizonte: SEBRAE/MG, 2008.

SECCHI, Leonardo. Políticas públicas: conceitos, esquemas de análise, casos práticos. 2. ed. São Paulo: Cengage Learning, 2014.

SOUZA, Celina. Políticas públicas: uma revisão de literatura. Sociologias, Porto Alegre, ano 8, n. 16, jul./ dez. 2006. 
SOUZA, Henrique lacovo Irineu de. O uso do índice de responsabilidade social como função controle de políticas públicas em Mato Grosso do Sul. 2010. 134f. Dissertação (Mestrado em Administração) Universidade Federal de Mato Grosso do Sul, Campo Grande, MS, 2010.

VASCONCELOS, Vitor Vieira; HADAD, Renato Moreira; MARTINS JÚNIOR, Paulo Pereira. Zoneamento Ecológico-Econômico - objetivos e estratégias de política ambiental. Gaia Scientia, João Pessoa, PB, v. 7, n. 1, p. 119-132, 2013.

\section{Sobre os autores:}

Thiago de Andrade Neves: Advogado, mestre em Administração da Escola de Administração e Negócios (ESAN/UFMS) e doutorando em Administração pela Faculdade de Economia, Administração e Contabilidade da Universidade de São Paulo (FEA/USP). E-mail: br.thiagoneves@gmail.com

Leandro Sauer: Doutor em Engenharia Elétrica pela UNICAMP, Professor da ESAN/UFMS. E-mail: leandro.sauer@ufms.br 